\title{
Sustaining the Ancient Olive Community: Strategies for Mediterranean Sustainable Development
}

\author{
Nicholas C. Zaferatos, Ph.D., AICP \\ Huxley College of the Environment, Western Washington University \\ MS/9085, Bellingham, WA. 98225 USA \\ Tel: 1-360-734-1883 E-mail: Nicholas.zaferatos@wwu.edu
}

The research is funded by the Anna Lindh Foundation for Dialogue between Cultures, Alexandria, Egypt.

\begin{abstract}
This article presents the findings of a six month investigation conducted by a network of six non-government organizations (NGOs) from five European-Mediterranean nations, representatives from five rural farming communities, and academicians from three institutions. The aim of the investigation was to identify strategies for reversing rural marginalization in Mediterranean communities through the establishment of sustainable forms of community development based on cooperative efforts in the production and trade of olive oil. Funded by the Anna Lindh Foundation for Dialogue Between Cultures, the investigation brought together knowledgeable community organizations, farming communities, and community development experts in order to address systemic problems that threaten the survival of rural agricultural communities. It was determined that regional economic cooperation had the potential of being an effective strategy for the long term revitalization of rural communities that have been disadvantaged by the effects of globalization. The investigation resulted in a sustainable development business strategy that promoted cooperative reliance among rural communities of the Mediterranean region.
\end{abstract}

Keywords: Sustainable agriculture, Sustainable economic development, Social justice, Community food systems, Fair trade olive oil, Mediterranean community development

\section{Introduction}

Civil society and the academic community have long acknowledged the need to work together in order to address ways in which emerging knowledge in sustainable development can be directly applied to benefit local communities. The EuroMed Sustainable Community Connections Project ("EuroMed project") was established in 2008 to address this need. The project was based on the belief that sustainable development can best be informed through an active collaboration among civil society, academic institutions, and beneficiary local communities. The project brought together six non-government organizations from five Mediterranean states to consider approaches for the sustainable revival of traditional agricultural economies.

The primary questions underlying the investigation were:

1.1) With the aid of civil society and academia, can the conditions causing the decline in rural agricultural communities be identified?

1.2) Can those conditions then be overcome by adapting sustainability principles in community development?

1.3) Can a system of cooperative economic development among diverse rural agricultural communities help overcome obstacles to their global market competitiveness and lead to increased benefits for local communities?

The EuroMed project was conducted as a series of four workshops that were held between December 2007 and May 2008. The first workshop, held in Athens, identified project objectives and the scope of the investigation. The project team agreed that the cooperative production of olive oil should be the focus of the project as olive oil is both the primary and traditional economic resource in each of the representative Mediterranean communities. The project was framed as an investigation of community development approaches that could reinvigorate traditional farming communities through sustainable forms of olive oil production while concurrently exploring ways to penetrate global markets. The Athens workshop also identified several persistent factors that have resulted in a reduction of agricultural productivity in rural communities, and, unless abated, could lead to the continued marginalization of those communities. 
During the second workshop, which was held at the Rockefeller Foundation Bellagio Center, Italy, participants sought to define rural sustainable development with respect to the existing conditions in each of the respective rural communities. These discussions resulted in the development of a framework for community development comprised of desirable outcomes and measurable indicators that could be used to guide each community's economic development. The third workshop, held in Tunisia, focused on the exchange of information regarding the particular conditions that local olive oil producers face. A conceptual model, based on the "fair trade" business model, emerged as the preferred organizational approach for the production and marketing of olive oil by a collective of rural communities.

In the final workshop, held in Kefalonia, Greece, the network partners evaluated the tentative conclusions of the research and entered into an agreement to facilitate community-centered sustainable development based on the fair-trade trade community development model.

\section{Five Rural Communities of a Common Heritage}

The five representative communities of Jloula (Tunisia), Ajlon, (Jordan), Mani (Greece), Kefalonia (Greece), and Ramallah (Palestine) are small, rural farming villages. Each community's economy is primarily based on the production of olive oil, a tradition that has sustained their villages for centuries. Although their economies continue to remain dependent upon agriculture, olive oil production has been appreciably reduced over the past several decades. Though the olive trees, some more than 1000 years old, continue to produce fruit, the majority of the orchards remain under harvested, the olives collected by an aging resident population, or abandoned altogether. Virtually all of the residual production is used for domestic consumption, though according to estimates from local producers, these village orchards have the potential for collectively producing several hundred tons of high quality olive oil.

Several principal obstacles that limit the production of olive oil were identified during the course of the workshops, including the lack of labor to support annual harvests and orchard maintenance and limited access to price competitive global markets. Additional obstacles to expanded production include access to capital and technology to support orchard maintenance, harvesting, processing, packaging, and product marketing; quality control testing; and technology necessary for the treatment of the waste stream from production processes.

The project team examined approaches for both increasing the production of olive oil and for directly exporting the product to consumer markets by employing innovative marketing strategies emphasizing the olive oil product as a high quality food commodity as well as highlighting the products' unique designation of origin as reflected by each individual producer community. It was agreed that a product line that tells the story of the cooperation among diverse Mediterranean rural communities could contribute to promoting consumer awareness of, and appreciation for, global sustainable development efforts. In 1992, the European Union created the Protected Designation of Origin (PDO) classification system to promote and protect regional food products that originate within the EU. A PDO designation describes foods which are produced, processed and prepared in a given geographical area and which emphasize localized knowledge and traditions. This designation helps to clearly identify products from geographically and culturally unique communities, thereby creating a distinct marketing advantage over products derived from bulk commodity markets.

\section{Research Inquiry}

An inquiry regarding the characteristics of rural olive oil producing communities was conducted in order to better understand the variables that affect the development of those communities. These variables include: 1) the role of agriculture as an attribute to a community's cultural identity and landscape; 2) the nature of olive oil production practices; 3 ) the causes that have led to rural abandonment; 4) the role of social justice, food security, and sustainability in a community's development; 5) the variables that contribute to a community's social wellbeing and resiliency; and, 6) the variables that limit economic productivity and access to global markets.

\subsection{Olive Oil as Historic Cultural landscape}

Olive oil represents one of the most important resources of the Mediterranean landscape. In fact, the geographic definition of the Mediterranean is often described as the region where olive cultivation occurs. The olive tree is amongst the oldest of known cultivated trees and was tended before written language was developed. In fact, records exist indicating that wild olives were collected by Neolithic People in Anatolia as early as 8500 B.C. Depictions of the olive appear throughout the Mediterranean on ancient pottery, coins and tomb decorations (IOOC 2008).

It is believed that olives were first cultivated simultaneously on the island of Crete and in the Levant, the eastern region of Mediterranean. Olives, as a source of wealth, were of tremendous importance to the Minoan 
civilization on Crete. Olive oil was a significant trade commodity and the Minoans exported olive clippings for cultivation, along with the oil itself, to Greece and to North African coastal communities. The Greeks elevated the olive and its oil to a status unrivaled by any other commodity. By 1500 B.C., Greece was the largest producer of olive oil in the ancient world. As the Greeks and the Phoenicians emigrated west and established colonies in Italy, France, Spain and North Africa, olive oil became the primary trade currency. By the $7^{\text {th }}$ Century B.C., as olive orchards flourished in Attica, laws were enacted that protected the olive trees of Athens. By the $5^{\text {th }}$ Century B.C., Athens became a center of Greek olive culture. Along with oil, Greece also disseminated techniques for olive cultivation across the Mediterranean. During this period, ancient philosophers, physicians and historians began classifying the olive botanically, standards were established to categorize the qualities of the various olives, and the medicinal and curative properties attributed to olive oil were expounded. By 400 A.D., the olive was flourishing throughout the Mediterranean and the Roman invention of the screw press would produce oil in the manner that would subsequently continue for 2000 years. In the 7 th Century A.D. the Prophet Muhammad advised his followers to regard olive oil as an essential component of health, noting more than 70 different diseases that the oil was believed to cure. In fact, throughout the Mediterranean, the belief that olive oil, leaves, and blossoms conferred strength, health, vitality and youth was widely held.

Olives also played a predominant role in the mythology and symbolism of the Mediterranean, representing, to various cultures, rebirth, light, tranquility, victory, wisdom, euphoria and wisdom. They were also regarded as a symbol of peace. Because they grow to be extremely old and are capable of continuously producing fruit, they became an ancient symbol of fertility as well. Greek mythology is particularly rich in references to the revered olive tree. In fact, many of the ancient Greek gods and goddesses were believed to have been born under the branches of the olive tree. Because of this, olive leaf wreaths were used to decorate accomplished soldiers, scholars, and athletes. Olive oil production, because it has been continuously practiced since antiquity, is deeply embedded in the nutritional, historical and cultural identity of the Mediterranean landscape.

\subsection{Forms of Olive Oil Productivity}

The economic viability of olive oil fluctuates depending on the scale of farms, competitiveness of the market, environmental constraints, and degree of governmental intervention. Though the economic benefits of olive oil production are increasingly being realized by large-scale intensive producers who exhibit a higher level of productivity, these often come at the expense of both traditional rural communities and natural ecosystems (Flora 2007). Industrialized forms of production have encouraged the movement of olive cultivation away from remote traditional olive growing regions, resulting in the marginalization of those rural communities.

The European Union (EU) produces about 70\% of the world supply of olive oil (European Commission 2004; IOOC 2008). Its five top producers, respectively, are Spain, Italy, Greece, Portugal and France. Increased production is attributed to a number of factors, including the intensification and mechanization of production; improvements to olive cultivation; the European Union's Common Agricultural Policy (CAP) support; and higher olive-oil pricing.

Forms of olive oil production that are associated with positive environmental, social and cultural outcomes are most often cited as the least economically viable form of cultivation (Clay 2004; Doukas 2001). These positive environmental and social outcomes include increased biodiversity, landscape conservation, water conservation, and retention of cultural heritage. Forms of oil production with the greatest positive environmental outcomes were found to average a net annual loss of about $€ 400$ per hectare while highly industrialized operations averaged an annual profit of about $€ 1,375$ per hectare (European Commission 2004). These economic disparities are the result of market competition coupled with EU subsidies that strongly favor increased production volume.

Olive oil production is comprised of three general categories of cultivation: traditional low-input groves; traditional high-input groves; and large high-input groves. Low input groves range from between 40 and 250 trees per hectare (Lunde 2007). These groves are typically located in remote mountainous areas, and have experienced a continuous decline in productivity. Traditional small groves are often terraced, and their under storey is typically maintained through grazing rather than through the use of herbicides or heavy tilling. These orchards generally receive little or no chemical fertilization, relying instead on the application of manure. Furthermore, pesticides and irrigation are rarely used. In these traditional groves, farmers rarely replace plants that exceed full productive capacity, preferring to preserve the rich legacy that olive trees contribute to the cultural landscape and to the history of the region. The olive groves associated with the project's case study communities are characterized as traditional low-input orchards. 
Low-input traditional olive farms potentially have the highest positive natural values in terms of biodiversity, landscape management, and cultural conservation. They also incur the least negative impacts regarding water conservation and other environment considerations while simultaneously supporting strong community cultural traditions through the harvesting of trees that are hundreds of years old.

Traditional high input olive farms are similarly located in hilly terrain and rolling plains and average between 80 and 250 trees per hectare. These high input groves produce a greater yield per tree by relying on farming techniques that involve repeated tilling, herbicides applications for the management of the under story, and the use of synthetic fertilizers and pesticide treatments. These groves are increasingly incorporating systems of drip irrigation in order to maximize fruiting and develop a heavier average weight per olive.

Intensive modern olive farms are typically located on plains, with a density of 200 to 400 trees per hectare. Under story management relies on the application of herbicides and orchards receive repeated pesticides treatment. Chemical fertilizers are typically applied through drip irrigation systems, and the orchards are often harvested using mechanized equipment. Economic, cultural, climatic and landscape variables compete to determine which agricultural practices a particular olive producer will employ. In the mountainous regions of the Mediterranean, steep terrain limits the use of mechanized equipment in olive groves, requiring a higher labor input. The dilemma that must be examined involves the ways in which positive, low input traditional practices might be augmented in order to more successfully compete with intensive practices.

\subsection{Rural Abandonment}

Since World War II, socio-economic forces and governmental policies have combined to encourage the intensification of agriculture and have aggravated the trend toward abandonment of remote agricultural communities (Barker 2002), particularly in EU nations. Traditional practices in sustainable agriculture are currently threatened by the intensified farming practices which have characterized Mediterranean agriculture during the post-war period (Eurostat 2007). While intensified agriculture does lead to higher productivity and economic profitability, it simultaneously results in negative social and environmental consequences. The abandonment of small agricultural communities diminishes sustainable traditional agricultural practices and results in an increased marginalization of those communities.

The resurrection of competitive agriculture in remote regions is a necessary step towards the survival of rural communities. The viability of communities that practice traditional low-input, low-yielding dry land cultivation is inextricably linked to their ability to compete with industrialized production in an increasingly competitive market. A challenge facing these vulnerable rural communities is the ability to not only identify forms of agriculture that are economically viable but that also have a positive effect on the community's cultural and ecological system.

In many European Union Mediterranean states, two phenomena are identified as causes of marginalization. The first is attributed to specific EU industrialization and urbanization policies that have drawn workers away from the countryside to industrial centers. The second is attributed to the rise of industrialized agriculture, creating a situation in which small rural farms cannot compete with farms that are dependent upon intensified agricultural practices. These policies have clearly contributed to the depopulation of rural areas. Since WWII, the model of economic growth which Mediterranean agricultural sectors have followed has resulted in pockets of intensive farming which are primarily located in coastal areas and in accessible valley regions. The European Union's current policies for rural development specifically aim to reverse the agricultural abandonment that is emblematic of the post war era. Sustainable agriculture and rural development policies are a response to problems faced by lagging agricultural regions (European Commission 2007).

Consistent with the broader framework of sustainable development, sustainable agriculture emphasizes the need to promote the health of human, economic, and natural resources simultaneously (Warner 2007). The concept of sustainability, when applied to agriculture in rural communities, recognizes the important interdependencies of people and their natural landscapes (Scherr et al. 2007). Embodying the principles of a holistic approach to development, sustainable agriculture is equally concerned with economic vitality, environmental preservation, and social equity, in contrast to prior decades' emphasis on maximizing product output. Sustainable development is achieved through agricultural practices that result in a steady increase in the vitality and stability of the community. Implicit in this approach is the notion that the path towards a community's successful economic expansion, as an endogenous form of development, should be rooted in the cultural history of the particular community and be responsive to the needs of the local population. 


\subsection{Social justice, food security and sustainability}

The EuroMed project also sought to identify approaches to sustainable community development that would simultaneously contribute to the creation of stronger relationships among diverse Mediterranean cultures. Through an examination of trans boundary economic cooperation and inter-community reliance, the project explored the concept of the reconfiguration of community economies. Such a paradigm could help to remold agricultural economies in a manner consistent with benign traditional environmental practices (Jackson 2002). It was viewed that principles of sustainability could be effectively applied to guide the reshaping of agricultural practices in order to produce both positive environmental and social outcomes in rural communities as first elaborated by the Brundtland Commission (Spector 2002).

Sustainable agriculture, as described by Lockeretz $(1990)$ exhibits several primary characteristics, including: the ability of local farming systems to endure indefinitely; the reduction or elimination of external materials; and the application of practices that are consistent with natural environmental systems processes. Since the post-war period, the production and marketing of foods has been governed by food and farm policies that have transformed staple foods, including olive oil, into export crops for global commodity markets. This reorientation of food systems subordinates the importance of the local community in the process of food production. The commoditization of food tends to negate the importance of place and culture, as well as the principles of sustainability (McMichael 1994).

In contrast to industrialized farming production that disconnects producers from consumers, fair trade and equal trade food production attempts to create new ways to link producers and consumers. Sustainable community development strategies can help reestablish producer and consumer linkages by emphasizing ecologically sound land use practices in the production of wholesome foods. Such a demand is rapidly increasing among conscientious consumer communities (Friedmann 2000, 2003, 2004; Escobar 1995). Approaches that can be used to further these objectives include farmer cooperatives, controlled appellation, product traceability, and labeling products by origin.

The reestablishment of viable agrarian rural communities that reintroduce diversified farming systems also experience a reduced social vulnerability by emphasizing community well-being and promoting community resilience (Birkmann 2006). Sustainable agrarian communities can build stable food systems that support local job creation and promote environmental stewardship (Kimbrell 2002). Such sustainable communities can be as informal as a small group of households with a common interest in producing food products sustainably, or as complex as a multi-national, intra-regional institution (Pretty et al. 1995), as proposed by the EuroMed project.

\subsection{Social Well-being and community resiliency}

The viability of rural communities is central to the health of their populations, as well as to the environment of those communities. The prevailing globalization model of economic development is dependent upon an export-oriented form of agricultural that generates far-reaching problems on a global scale (Cavanaugh 2002; Porritt 2006; Robbins 2008). Industrial agriculture has been shown to be both directly and indirectly linked to widespread contamination of rivers, soil erosion, depletion of fresh water supplies, chemical imbalances in soils and surface and groundwater, loss of seed varieties, and acceleration of global climate change. The cumulative impact of such deleterious trends reflects the experiences of Green Revolution technologies which increased productivity while elevating social and environmental costs (Norberg-Hodge et al. 2002; Pretty 1995).

Integral to sustainable community development are social justice considerations that reaffirm the priority of community benefits along with the long term stability of the community's economic structures. In light of the growing inequality inherent in global economic development, the pairing of a community's well being to its economic stability is emerging as a critical component of planning for rural development. For much of human history, and continuing in many indigenous and traditional societies today, concepts of inviolable common resources and shared community use have been understood as basic community values. Peoples who live in close relationship with their local region engender not only intricate place-based knowledge, but also a well defined conservation ethic. That ethic tends to emphasize cooperation, cross-generational communication and learning, concern for the well-being of future generations, and restraint from exploiting natural resources (Posey 2001). The shared wealth of knowledge within these communities also provides them with an effective capacity to respond to changing circumstances or disasters.

Such primary relationships have not always been politically favored (Wolf 1982; Robbins 2008). Even well intentioned community economic development efforts of the past have often been misdirected due to both a narrow focus on interventions directed to single issues, and to the disregarding of intricate livelihood systems that represent the true wealth of rural communities. As a result, such efforts have had mixed outcomes. 
Increasingly, the complex dimension of small communities has come to be understood as a central factor of their resilience (Helmore and Singh 2001). Ethnographic and empirical research indicates that small-scale producer communities are remarkably resilient and local food producers both survive and thrive by building synergies, holistic arrangements, and resilience within their communities, especially in the face of adverse conditions (Gonzales 2001; Shiva 2000; Wilken 2006).

A complex combination of place-based experiences and knowledge persists in rural and small-scale communities as rural peoples tend to share common basic values that are concomitant with their means of production (Kearney 1996; Wolf 1982). Studies have found that both social vitality and economic advantages are much stronger in communities that are comprised of family farms, compared to those comprised of corporate-owned industrial agriculture (Goldschmidt 1947). It stands to reason, then, that when community interdependence is strong, the community's sense of well being is strengthened as well.

Several conditions have been observed that contribute to the sustainability of small agricultural communities (McKibben 2007; Norberg-Hodge 2000). First, development in small communities tends to essentially be local, relying upon internal community knowledge as well as external knowledge that is introduced to the community. Small communities also tend to be highly participatory, and tend toward long term views that emphasize a community ethos and welfare. Furthermore, the community's wellbeing is often viewed as being of paramount importance in community development, and therefore is given greater consideration. Seen in this light, economic systems play a core role in both maintaining and regenerating the community's social stability (Ikerd 2005; Porritt 2006).

The movement toward sustainable farming communities also involves the linkage between the well being of the producing community and the nutritional and social wellbeing of the consumer community. Concern for both healthy foods and healthy communities, along with a growing understanding of their interconnectedness, is evident by the growth in organic farming, fair trade products, farmer's markets, and the desire for direct relationships among producing communities and consumer economies (Pollan 2006). A host of new concepts that reflect agricultural ethics, including the slow foods movement, has found its way into public discourse in a very short period of time (Pollan 2008). For goods that cannot be produced locally, such as olive oil, new trade arrangements are necessary that allow consumers to make conscientious choices about their food purchases. One trade alternative is through a network of cross-border relationships built on fair or direct exchange that results in reciprocity among producing and consuming communities (Millard 2007). The principles of fair exchange, now common in coffee production and exchange, can be extended to other producing communities. As new consumer markets are introduced to traditional societies, new avenues for the distribution of their socially contributive and nutritional foods emerge (Burkham 2004; Loureiro \& Lotade 2005; Mann 2008). In the process, consumers are able to establish new forms of connectedness to the production and source of their food.

The redirection that is required for establishing new producer-consumer linkages may be difficult to achieve without adjustments to market distribution mechanisms (Ikerd 2005; Kitching 2001). In order to reverse the current destabilizing system of food commodity exchange and the further marginalization of rural communities, discovering alternative systems for interdependent good exchange becomes critical.

\subsection{Engaging in the international marketplace}

In order to address both the needs of multiple participating olive oil producer communities in the Mediterranean region, as well as of consumer communities, a viable and appropriate community development model is necessary. Such a model requires a business approach that is guided by sustainable development principles (Redclift 1988). Fair trade business schemes emphasize trade that promotes the inclusion of marginalized farming communities in global markets through the building of long term relationships (Renard 2005; Rocca 2005). It has been observed with other food commodities that such ventures, primarily due to their small scale and the ability of small farmers to develop cooperative production practices, are viable. In some cases, fair trade products achieve significant market shares (Hilson 2008). The fair trade banana market in Switzerland, for example, has attained a $49 \%$ market share, and fair trade coffee has attained a $20 \%$ market share in the UK (De Ferran \& Grunert 2007). Equally important, fair-trade certification often requires adherence to core community sustainability principles. To obtain a fair trade certification under the Fair-trade Labeling Organization (FLO), organizations are required to meet multiple community building criteria, including:

- Fair and stabilized pricing

- Equal employment and opportunity for advancement

- Environmentally sustainable practices 
- Long term trade relationships emphasizing public accountability

- Healthy and safe working environments

- Technical and financial assistance to producers

Surveys of fair trade enterprises show that they predominantly deal with producer organizations rather than with individual farmers (Mann 2008). The main objective of fair trade organizations is to effectively assist local producers to engage in advantageous international trade through which most of the revenue, derived from prevailing premium prices, is returned to the producers. In addition, a portion of the distributive earnings is reinvested in the community's infrastructure and social welfare. The EuroMed project's development model reflect these concerns, namely the access of competitive export markets for its olive oil products, and the redistribution of gains in order to support the communities' long term sustenance. Such a model requires a system of organizational coordination that can ensure that economic return is maximized and the benefits are equitably distributed to participating communities (Hemmati 2007; Chechetto-Salles \& Geyer 2006).

\section{Benchmarking Sustainability}

Defining and achieving sustainable development has become one of the major policy challenges of our generation (Eber 2002). A process of development is involved in which economic prosperity is integrally linked to social and environmental integrity in order to produce equitable outcomes and the preservation of community culture (Butler 1998; Wheeller 1993; WCED 1987). While social values were implicit in the core idea of sustainability (European Commission 2007), they were rarely explicitly stated or clearly defined (Innes \& Booher 2000). New economic models are needed that are infused with the social considerations and values of affected communities. A starting point for defining Mediterranean sustainable community development incorporates an integrated view of a community's development traditions, its sustaining economic base, its cultural maintenance requirements, and its self defined priorities for development. The results should contribute to a community's social cohesion as well as its long term security (Porritt 2006; Cavanaugh, et al 2002; Bopp and Bopp 2006).

A widely accepted method for measuring sustainability is through the use of defined outcomes and benchmark indicators. Outcomes represent desired end states in a community's development process. A benchmark indicator is a measurement that provides a point of reference for a community's development state in relation to its desired future state (Wheeller, 1993). The relative weight and importance assigned to sustainability indicators should be carefully considered in light of the particular conditions and priorities within each stakeholder community (Hall 1998).

The EuroMed project identified an initial set of outcomes that reflect the economic, social, and environmental justice priorities that were regarded as important to each of our representative communities. It was agreed that these outcomes would serve as guiding principles in the development of a Mediterranean olive oil trade economy. Six outcomes are accompanied by sixteen indicators as measurements for the attainment of the outcomes (figure 2). The outcomes and their accompanying indicators serve as a framework for developing a community based Mediterranean olive oil economy:

4.1 Community self governance outcome - the first outcome concerns the organization of a community's empowerment structure under which development is undertaken. The outcome emphasizes a democratizing process of community engagement and involvement by encouraging the broadest possible level of participation by community members.

- Indicator of participation - measuring the frequency and degree of community engagement and the level of participation in the economic activity. Procedures should be established to accurately record community participation in decision making regarding the operation of economic activities and distribution of benefits. Multiple forms of community response should be provided for direct participation by farmers, producers, laborers, and the general community.

4.2 Economy outcome - the economy outcome seeks to optimize income flows in order to benefit individual producer households, workers, and the broader community.

- Indicator of benefits to producer households - measuring data on employment and income, and "quality of life" indexes to producer households.

- Indicator of worker benefits - measuring compliance with international certification rules (such as FTO, ICO and UN standards) to ensure humane working conditions and fair, livable wages. 
- Indicator of local capacity - measuring the equitable profit distribution and investments in the community.

4.3 Social and cultural outcome - the social and cultural outcome promotes the integrity of the community and the enhancement of cultural heritage and family well being.

- Indicator of adequate local food supply - ensuring the adequacy of supply of olive oil to maintain the dietary function of the community, measured in terms of product affordability and availability.

- Indicator of rural abandonment - monitoring the number of people returning and remaining in the community, and the rate of migration.

- Indicator of cultural heritage - measuring the effectiveness of product marketing campaigns, curriculum programs in schools, workshops, festivals, and other activities that promote knowledge of, and produce positive impressions about, local producer communities.

- Indicators of family wellbeing - increasing family connectivity and inclusion of women and youth in economic activities measured by increases in wages and employment rates, and by Diaspora connectivity.

- Indicators of non-exploitive relations - measuring the ability of workers to voice opinions and concerns, the effectiveness of systems for the inspection and monitoring of worker conditions and worker complaints, and the inclusion of non-native workers' sense of "belonging" to the community.

4.4 Environmental outcome - the environmental outcome emphasizes the application of management practices to achieve environmentally benign processes in production, agricultural restoration and regeneration, and increased community resiliency to hazards.

- Indicator of environmental benign processes - measuring enterprise operations that achieve quality compliance and certification standards for organic production, and reduced impairment to air, water quality, and other natural resources with the goal of achieving "zero waste" in product production and operations.

- Indicator of regenerative agriculture - measuring the regeneration of agricultural resources through soil and water testing, and management practices that promote bio diversity.

- Indicator of resiliency to hazards - measuring the assessment of community response to risks from natural hazards, earthquake, and fire hazards as an integral element in community planning.

4.5 Production quality outcome - the attainment of high product quality is measured through indicators that establish product traceability and that emphasize local community knowledge.

- Indicator of traceability - establishing the certification of product origin and traceability in marketing and labeling through independent testing laboratories.

- Indicator of local knowledge - measuring effectiveness of educating consumers about local traditions and knowledge in orchard management, olive oil production, and community development goals through product marketing.

4.6 Global partnerships outcome - the global partnership outcome seeks to foster peace and justice outcomes both among Mediterranean producer cultures and beyond by promoting direct linkages with international consumer communities.

- Indicators promoting peace and justice in the Mediterranean region - measuring degree of exchange of technology and traditional knowledge among producers in olive orchard management, harvesting, and production practices, and encouraging direct, cross cultural connection among producer communities.

- Indicator of consumer and producer linkage - measuring the types and amount of contact between consumer and producer communities, such as through educational materials describing producer communities, agro-tourism and youth exchange programs.

\section{Conclusion and Next Steps}

The EuroMed project's overarching objective was to conceive of a culturally appropriate and economically viable form of sustainable community development that reflected the economic potential of each of our representative producer communities. The project sought to advance the principles of the Barcelona Declaration by promoting systems of cooperative commerce that encourage the creation of equitable and socially responsible global trade among peoples of the Mediterranean region. The process that was employed reflected the view that 
beneficial development should be shaped by building solidarity among communities of the Mediterranean and global consumer communities. New forms of community partnerships were suggested as a path towards improving the living conditions of marginalized communities and reducing the development gap that is prevalent throughout the European-Mediterranean region.

To achieve these community development ends, the project emphasized the development of a cooperative form of economic activity for the mutual benefit of a consortia of rural farming communities, which could be expanded to include other producer communities in the future. As the "Mediterranean" is geographically defined as the region "where the olive grows," the expansion of olive oil production naturally emerged as the most viable economic opportunity upon which to forge new economic relationships.

The community-based organizational structure for enterprise development (CBO) provides an ideal operational model to support the coordination of olive oil producer communities that operate in different Mediterranean states. The community-based organization would serve to facilitate the production and export of products, ensure consistency in product quality, and oversee the equitable distribution of community benefits. In order to coordinate the efforts of multiple community-based organizations throughout the Mediterranean region, a "Mediterranean Fair Trade Olive Oil Partnership" (MedFTO) is being proposed that would orchestrate the production and distribution of olive oil products from multi-state community organizations (AWISHhellas 2008). The MedFTO would also function as a facilitator among consumer markets and producers, coordinate production supply and distribution, negotiate product export and pricing contracts, and develop marketing branding to promote the unique products from each individual producer community. Based on the conceptual MedFTO development model, as market development expands, additional producing communities would be encouraged to participate, with the longer term goal of providing a wide array of Mediterranean fair trade olive oil products. A MedFTO board of directors, comprised of a representative from each producer community, should be organized to:

- Support each community based organization through education and business consultancy

- Foster producer communication and exchanges

- Promote producer community cultural identity under a "protected designation of origin" classification

- Mediate international markets, export compliance, licensing, and fair trade certification

- Manage financing, product delivery, and profit distribution among community-based organizations

- Ensure accountability, transparency and overall product quality

- Monitor compliance of sustainability objectives, and

- Implement strategic and tactical development plans

Target markets would initially focus on "consumer responsible" niche markets, such as consumer food cooperatives, and other consumer owned and managed markets that emphasize fair trade, organic products, and products of origin. The MedFTO product brand and promotional literature should emphasize both fair trade and the unique characteristics of individual producer communities. A strategic marketing objective would be the education of consumers so they become aware of the producer communities' sustainable development objectives. Educational displays and product labeling should convey the cooperative's objective of promoting global peace and understanding through economic cooperation among peoples from varied cultures and religions within the Mediterranean region.

The EuroMed workshops resulted in the formulation of a Mediterranean-centered model for community development guided by a set of sustainability outcomes. The model serves as a guide for building cooperative and interdependent economies that 1) advance economic, environmental, and social equity, 2) reflect the common values, traditions, needs, and priorities of local communities, and 3) promote the interests of marginalized peoples. The model represents a self reliant approach to community development as it builds upon an underutilized but ubiquitous resource - the olive and its people.

Building upon the principles of fair exchange, the formation of a community-based Mediterranean economy based upon the production and distribution of olive oil fosters a new regional approach to food production and exchange with the hope of improving conditions in marginalized communities. Such solidarity among producer communities would not only serve as a pathway towards building sustainable economies but would encourage greater community control over essential economic resources, the sharing of precious traditional knowledge, and the attainment of important social and environmental justice ideals. 
The EuroMed partners concluded the workshops with an agreement to actualize the Mediterranean Fair Trade Olive Oil Partnership model. A memorandum of understanding was entered into by the partner NGOs in order to undertake a pilot project in 2011 to test the research hypothesis. The EuroMed network would provide technical assistance to the pilot project community, assist in identifying sources of start up capital to fund the pilot program, identify consumer markets, negotiate sales agreements for olive oil products, and help the community finance and organize its enterprise operations.

As olive oil has been such an integral part of their culture and history, it seems both intuitive and logical that, by playing an instrumental role in creating a sustainable future for the peoples of the Mediterranean, the illustrious legacy of the olive will light the way forward.

\section{Acknowledgements}

The author wishes to acknowledge the contributions of the project's civil society partners: A World Institute for a Sustainable Humanity (AWISHhellas, Greece), Association for the Protection of Nature and Environment, (APNEK, Tunisia), Land and Human to Advocate Progress (LHAP, Jordan), Palestine Hydrology Group (PHG, Palestine), Me.Dia.Te (Italy), and the Association for Cooperation on Sustainable Development and Construction in the Mediterranean (SD-MED, Greece). The project's academic institutional partners include: The United Nations University (Amman), The Hellenic American University (Athens), and Huxley College of the Environment, Western Washington University (USA). Funding for the investigation was provided by the Anna Lindh Foundation, Alexandria, Egypt. Contributors to the project investigation included Theodoris Benetatos, (IMI University, Luzern, Switzerland), Gigi Berardi (Western Washington University), James Loucky (Western Washington University, Eileen Hoesley (Hellenic American University), and Cynthia Zaferatos (AWISHhellas).

\section{References}

A World Institute for a Sustainable Humanity - Hellas (AWISHhellas). (2008). EuroMed project briefing. Alexandria: Anna Lindh Foundation.

Barker, D. (2002). Globalization and industrial agriculture. In A. Kimbrell (Ed.), The fatal harvest reader: The tragedy of industrial agriculture (pp. 249-263). Washington: Island Press.

Birkmann, J. (2006). Measuring vulnerability to promote disaster-resilient societies: conceptual frameworks and definitions. In J. Birkmann (Ed.), Measuring vulnerability to natural hazards: towards disaster resilient societies (pp. 9-54). New York: United Nations University Press.

Bopp, M., \& Bopp, J. (2006). Recreating the world: A practical guide to building sustainable communities. Cochrane AB: Four Worlds Press.

Burkham, J. (2004). A local response to globalization: the study of a fair trade coffee community in Chiapas, Mexico. Bellingham, WA.: Western Washington University.

Butler R. (1998). Sustainable tourism - looking backwards in order to progress? In Sustainable tourism: A geographical perspective, ed. C.M. Hall \& A.A. Lew, 25-34. Essex: Longman.

Cavanaugh, J. (2002). Alternatives to economic globalization: report of the international forum on globalization. San Francisco: Berrett-Koehler.

Clay, J. (2004). World agriculture and the environment: A commodity-by-commodity guide to impacts and practices. Washington: Island Press.

Chechetto-Salles, M., \& and Geyer, Y. (2006). Community based organization management. Handbook series for community based organisations. Pretoria: Institute for Democracy in South Africa (IDASA).

De Ferran, F., \& Grunert, K. G. (2007). French fair trade coffee buyers purchasing motives. An exploratory study". Food Quality and Preference, 18, 218-229.

Doukas, A. (2001). Organic farming in Greece: problems, trends, prospects. Kefalonia, Greece: TEK.

Eber S. (2002). Guidelines for integrating sustainability into the undergraduate curriculum: leisure and tourism. London: University of North London \& Tourism Concern.

Escobar, A. (1995). Encountering development: the making and unmaking of the third world. Princeton: Princeton University Press.

European Commission. (2004). The common agricultural policy explained. Germany: European Commission Directorate General for Agriculture. 
European Commission (2007). A sustainable future in our hands. EU Sustainable Development Guide. Directorate-General for Agriculture and Rural Development, Brussels.

Eurostat (2007). Measuring progress to a more sustainable future. Monitoring report. EU Sustainable Development Report. Brussels.

Flora, C. B. (1990). Sustainability of agriculture and rural communities. In C. A. Francis, C. B. Flora \& L. D. King (Eds.). Sustainable agriculture in temperate zones. Hoboken, NJ: John Wiley \& Sons Inc.

Friedmann, H. (2000). What on earth is the modern world-system? Foodgetting and territory in the modern era and beyond. Journal of World-Systems Research, vi, 2, 480-515.

Friedmann, H. (2003). Eating in the gardens of gaia: envisioning polycultural communities. In J. Adams (Ed.), Fighting for the farm: rural America transformed. Philadelphia, PA: University of Pennsylvania Press.

Friedmann, H. (2004). Feeding the empire: the pathologies of globalized agriculture. In C. Leys (Ed.), The empire reloaded: Socialist register. New York: Monthly Review Press.

Goldschmidt, W.R. (1947). As you sow: three studies in the social consequences of agribusiness. Montclair NJ: Allanheld, Osmun and Co.

Gonzalez, R.J. (2001). Zapotec science: farming and food in the Northern Sierra of Oaxaca. Austin: University of Texas Press.

Hall C.M. (1998). Historical antecedents of sustainable development and ecotourism: new labels on old bottles? In C.M. Hall \& A.A. Lew (Eds.), Sustainable tourism: a geographical perspective (pp. 13-24). Essex: Longman.

Hemmati, M. (2007). Multistakeholder partnerships. In S. J. Scherr \& J. A. McNeely (Eds.), Farming with nature (pp. 344-357). Washington: Island Press.

Helmore, K., \& Singh, N. (2001). Sustainable livelihoods: building on the wealth of the poor. Bloomfield CT: Kumarian.

Hilson, G. (2008). Fair trade gold. Geoforum, 39:1, 386-400.

Ikerd, J. (2005). Sustainable capitalism: a matter of common sense. Bloomfield CT: Kumarian.

Innes, J., \& Booher D. (2000), Indicators for sustainable communities. Institut National de la Statistique et des Etudes (INSEE). [Online] Available : http://www.insee.fr/french_population.html (February 2, 2008).

International Olive Oil Council (IOOC). [Online] Available: http://www.internationaloliveoil.org. (March 16, 2008).

Jackson, W. (2002). Farming in nature's image: natural systems agriculture. In A. Kimbrell (Ed.), The fatal harvest reader: The tragedy of industrial agriculture (pp. 65-75). Washington: Island Press.

Kearney, M. (1996). Reconceptualizing the peasantry. Boulder: Westview.

Kitching, G. (2001). Seeking social justice through globalization: escaping a nationalist perspective. State Park: Pennsylvania University Press.

Kimbrell, A. (2002). Corporate lies: busting the myths of industrial agriculture: seven deadly myths of industrial agriculture. In. A. Kimbrell (Ed.), The fatal harvest reader: The tragedy of industrial agriculture. Washington: Island Press.

Lockeretz, W. (1990). Major issues confronting sustainable agriculture. In C. A. Francis, C. B. Flora \& L. D. King (Eds.), Sustainable agriculture in temperate zones. Hoboken, NJ: John Wiley \& Sons Inc.

Loureiro, M., \& Lotade, J. (2005). Do fair trade and eco labels in coffee wake up consumer conscience? Ecological Economics (pp. 129-138).

Lunde, A. (2007). Rural development and sustainable agriculture in the European Union Mediterranean: A case study on olive oil production in Kefalonia, Greece. Thesis. Bellingham, WA: Western Washington University.

Mann, S. (2008). Analyzing fair trade in economic terms. Journal of Socio-Economics, 37:5.

McKibben, B. (2007). Deep economy: the wealth of communities and the durable future. New York: Times Books, Henry Holt and Company.

McMichael, P. (1994). Global restructuring: some lines of inquiry. In P. McMichael (Ed.), The global restructuring of agro-food systems (pp. 277-300). Ithaca and London: Cornell University Press. 
Millard, E. (2007). Restructuring the supply chain. In S. Scherr and J. McNeely (Eds.), Farming with nature (pp. 358-377). Washington: Island Press.

Norberg-Hodge, H. (2000). Shifting direction: from global dependence to local interdependence. International Berkeley: Society for Ecology and Culture.

Norberg-Hodge, H., Merrifield, T., \& Gorelick, S. (2002). Bringing the food economy home: local alternatives to global agribusiness. Bloomfield CT: Kumarian.

Pollan, M. (2006). The omnivore's dilemma: a natural history of four meals. New York: Thorndike.

Pollen, M. (2008). In defense of food: An eater's manifesto. New York: Penguin Press HC.

Porritt, Jonathan (2006). Capitalism as if the world matters. London: Earthscan.

Posey, D.A. (2001). Biological and cultural diversity. In . Luisa Maffi (Ed.), On biocultural diversity: linking language, knowledge, and the environment (pp. 379-397). Washington: Smithsonian Institutions.

Pretty, J., Guijt, I., Scoones, I., \& Thompson, J. (1995). Regenerating agriculture: The agroecology of low-external input and community-based development. In J. P. O'Keefe and L. Timberlake (Eds.), The earthscan reader in sustainable development (pp. 125-145). London: Earthscan Publications Ltd.

Robbins, R. (2008). Global problems and the culture of capitalism. Boston: Pearson.

Redclift M. (1988). Sustainable development and the market: a framework for analysis, Futures 20:6, 638.

Renard, M.C. (2005). Quality certification, regulation and power in fair trade. Journal of Rural Studies 21:4, 419-431.

Rocca, F. X. (2005). Slow down and smell the garlic: An Italian university focuses on the craft of creating food and pleasures of the palate. The Chronicle of Higher Education.

Scherr, S. J., Milder, J. C., \& and Inbar, M. (2007). Paying farmers for stewardship. In S. J. Scherr \& J. A. McNeely (Eds.), Farming with nature (pp. 378-398). Washington: Island Press.

Shiva, V. (2000). Stolen harvest: the hijacking of the global food supply. Cambridge MA: South End.

Spector, R. (2002). Fully integrated food systems: regaining connections between farmers and consumers. In A. Kimbrell (Ed.), The fatal harvest reader: The tragedy of industrial agriculture (pp. 288-294). Washington: Island Press.

Warner, K. D. (2007). Agroecology in action: extending alternative agriculture through social networks. Cambridge, MA: MIT Press.

Wheeller B. (1993). Sustaining the ego. Journal of Sustainable Tourism 1:2, 121-129.

Wilken, G.C. (2006). Good farmers: traditional agricultural resource management in Mexico and Central America. Berkeley: University of California Press.

Wolf, E. (1982). Europe and the people without history. Berkeley: University of California Press.

World Commission on Environment and Development (WCED). (1987). Our common future (the Brundtland Report). London: Oxford University Press. 


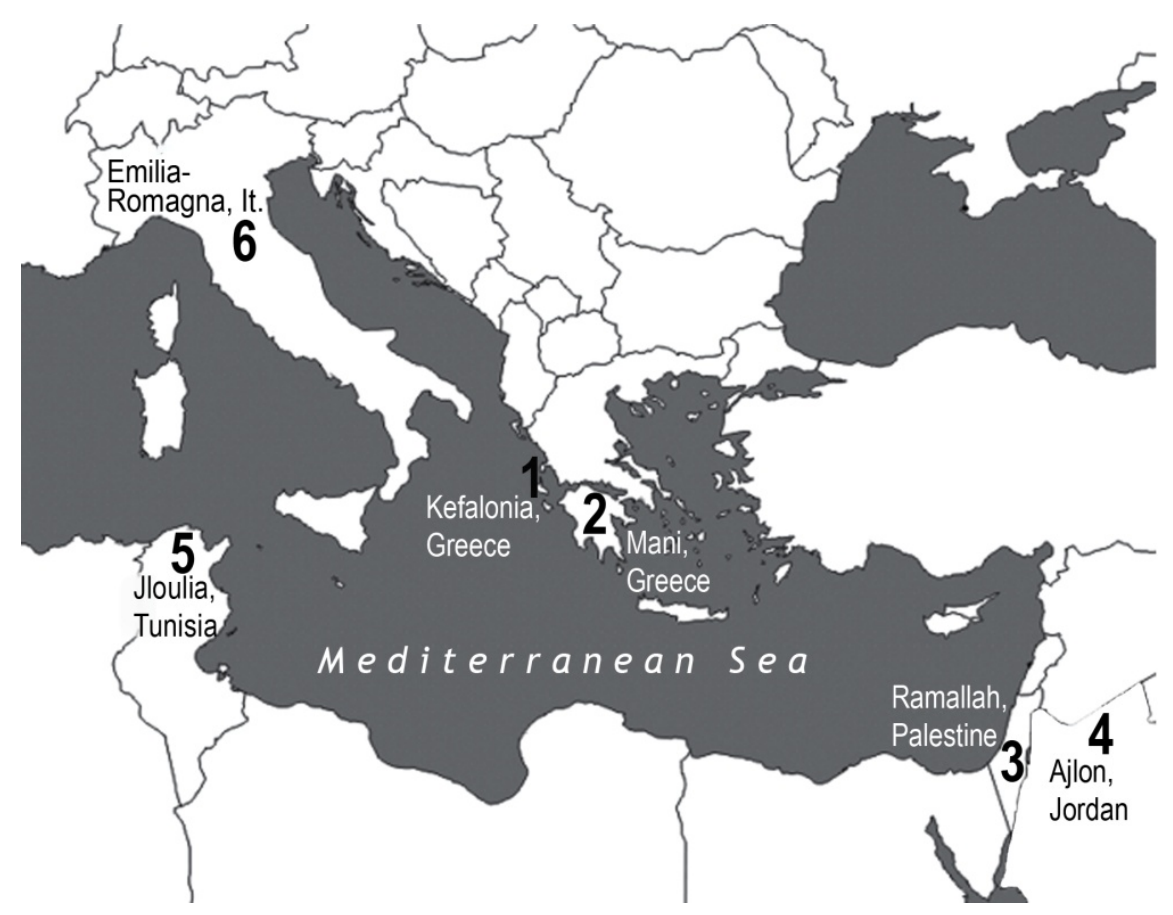

Figure 1. EuroMed cooperating farming communities in the Mediterranean Region

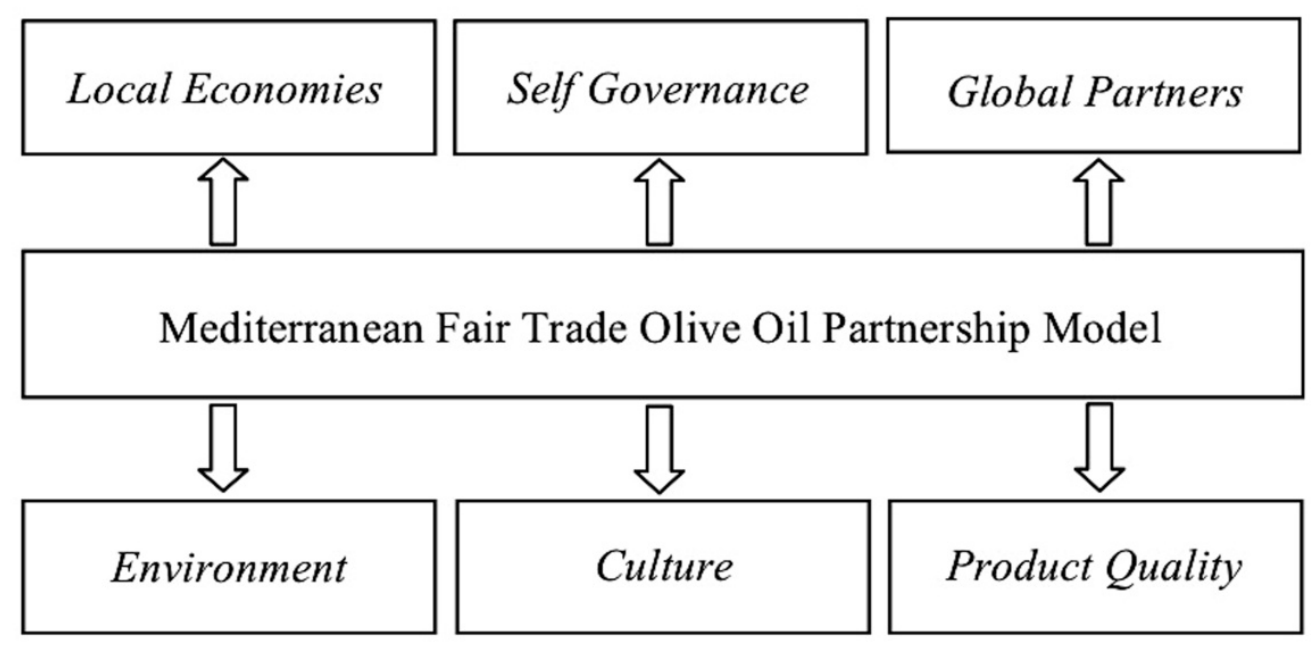

Figure 2. A schematic model showing outcomes in Mediterranean fair trade sustainable development 